\title{
The modern crisis of European culture and historical cognition
}

\author{
Maxim Bakhtin ${ }^{1, *}$, Marem Dolgieva ${ }^{2}$, and Natalya Yarmolich $^{3}$ \\ ${ }^{1}$ International Professor Club (Italy) 97100, via Velardo, 35, Ragusa, Italia \\ ${ }^{2}$ Ingush Research Institute named after Ch.E. Akhrieva 7 I. B. Zyazikov Ave., Magas, Republic of \\ Ingushetia, 386001, Russia \\ ${ }^{3}$ Pskov State University, 2, Lenin Place, Pskov, 180000, Russia
}

\begin{abstract}
The Article studies the reasons for loss of historical knowledge of the leading position in the humanities knowledge system in the crisis epoch of the European Culture at the beginning of the twentieth century. It is concluded that its main reason was the failure of the idealistic romanticism value system to form an elite adequate to social challenges. It has led to social disturbances and a large-scale reappraisal of values. Historical knowledge was put on the back burner by the new social sciences. Based on the concept of cynical reason of Peter Sloterdijk, the continuance of the current position of historical knowledge in culture with respect to its position at the beginning of the twentieth century is shown. It is concluded that today the most popular element of historical knowledge is an event available for direct experience. The reason for this situation is the cynicism of culture, understood as an inability to evaluate and act. The motive of parting with the past has acquired an unambiguously positive sound, having the other side of an enthusiastic anticipation of the future. The idea that the "old" times have passed, and the "new" modernity precedes with an even more "modern" times - "post-modernity", is present not only thematically, but defines the discourse everywhere, including media reports, advertising, everyday communication, etc. The question concerning place of history and historical knowledge from the very beginning was one of the central questions discussed in connection with the crisis.
\end{abstract}

\section{Introduction}

For the epistemology of modern social-historical knowledge, the period of the crisis at the turn of the nineteenth and twentieth century's is essential, since a set of cultural and social binds which determines the current place of historical knowledge in the social knowledge system was formed at that time. The purpose of this Article is to study the reasons led to loss of historical knowledge in this period of its leading position in the humanities and culture system in general, as well as some philosophical interpretations of this phenomenon.

The crisis or decline of European culture was announced in the second half of the nineteenth century, primarily by Friedrich Nietzsche, Fyodor Dostoyevskiy and Lev Tolstoy.

\footnotetext{
* Corresponding author: universdoktor@gmail.com
} 
Originally the prophecies of the crisis were perceived as something eccentric, but the catastrophic events of the First World War and its consequences bring the crisis into reality for hundreds of millions of European culture-bearers. The most significant concepts that discuss the crisis challenges belong to Oswald Spengler, Karl Jaspers, Edmund Husserl, Arnold Toynbee, Martin Heidegger, Jose Ortega y Gasset, Nikolai Berdyaev, Lev Shestov, Reymond Aron, Theodor Adorno, Michel Foucault, Jürgen Habermas, Peter Sloterdijk. Interest in the crisis epoch persisted throughout the twentieth century, and it continues to this day.

The terms "decadence" and "modern" expressed a new self-sentiment, and the motive of parting with the past acquired an unambiguously positive sound, having an enthusiastic anticipation of the future on its other side. The idea that the "old" times have passed, and the "new" modernity precedes with an even more "modern" times - "post-modernity", is present not only thematically, but defines the discourse everywhere, including media reports, advertising, everyday communication, etc. The question concerning place of history and historical knowledge from the very beginning was one of the central questions discussed in connection with the crisis. Let us briefly describe the historical knowledge path in European culture from the very beginning of Renaissance Epoch in order to understand why this is so.

Unquestionably that the European culture of Modern Age uses historical knowledge and has historical consciousness as the fundamental bases of the structures of its rationality and practice. This position can be justified both existentially-ontologically and culturallyhistorically. In the latter sense, the source of the historical consciousness of the Modern Times is the humanism of the Renaissance Epoch, which marked a radical renovation of the European man identity. History as a science and as such producer of information on the past, which gives the maximum possible guarantee in their uprightness, has received a unique status here, which can only be compared with the status of philosophy in the ancient Greek polis. History has become the center and foundation of self-consciousness, both as an individual and as a society. The answer to any question concerning the essence and purpose of human, society, and even nature existence had to contain a reference to historical certainty, out of which this question simply lost its meaning. The Modern Times rationalism, the rise of which was associated with the natural science development, partly raised doubts about the value of historical one, but in the Enlightenment Epoch these doubts were replaced by giving historical knowledge even greater significance as part of a complex of ideas promised the society constitution on the basis of civil order, justice and reason.

\section{Materials and methods}

Romanticism as a largely counter-enlightenment movement, relegated to the background all those goals of historicism that could be useful for constitution of natural science and civil reason, concentrating on ethical and aesthetic ideals generation. Provided that the history, within the framework of the system of education and upbringing prescribed by romantic idealism, acquired a dominant character.

\subsection{Relevance}

Now it is necessary to take into consideration a number of social-political circumstances. By the end of the nineteenth century, the romantic idealism values were come in obvious collision with the rapid growth of natural science and technology, as well as with significant social changes in the leading countries of European civilization. With the capitalism development, a crisis of the old elites, a crisis of the traditional society foundations are coming, and the mass is entering the arena of social struggle - a new subject of social reality. The masses appearance confuses all the social plans of the elites nourished by romantic 
idealism. The mass is not ready to accept any ideas, values, cultural or social skills in the complex forms in which they were presented to the elites. If the Enlightenment was not yet designed for the masses, intended for the elite and the middle class, then the social attitudes of romantic idealism least of all suggested concern on how the majority would behave. As in pre-capitalist times, it was considered neither prominent nor influential, although by the middle of the nineteenth century it was obvious to an fair-minded observer that the situation had changed. This was so inconsistent with the prevailing cultural and social attitudes of the elite that many of its representatives simply refused to see the new reality. The anger caused by the masses emancipation and capitalism as the cause of this phenomenon turns out to be the motive that determined the social views of both Tolstoy and Nietzsche, both Russian Slavophils and the Western European right. Some politicians which are representatives of the old elite, such as Otto von Bismarck, did not hide that they put up with the new reality phenomena - parliamentarism, the press, the social democratic movement - as an inevitable evil [1], and others - the political elite of Czarist Russia - until their last hour did not want to put up with them in any form. The unwillingness of the old elites to accept the masses appearance as a historically inevitable phenomenon, which goes beyond rational behavior, and the resulting inability to reorganize social and political reality in a timely and correct manner, were among the reasons that led to the social and cultural situation in which the catastrophe of the First World War became possible.

How to explain this behavior of the elites? For most of the nineteenth century, the elites of developed countries were brought up by a well-thought-out and well-established system of education and upbringing in the spirit of the Enlightenment prepared by Romanticism. This system, formed primarily in Germany, Great Britain, and France, was based on classical education. It was assumed that with its help it would be possible to bring up a person of true culture, i.e. to obtain a harmony of perfect intelligence, noble aesthetic sense and high moral qualities. This should lead to such study of literature, history, art of antiquity, as well as classical languages, which, developing the student's intelligence, will introduce him to the "Golden Age" of European civilization, to the unclouded forms of the beautiful and morally perfective. Moreover, this study was not at all introductory. Thus, aspirant to a scholarship allowance to study at the University of Oxford passed several exams, including the composition of poems in ancient Greek and Latin [2]. Clearly, not all candidates passed such exams brilliantly, but the classical and continuing university education in the nineteenth century was not an education for a certain set of people, as it was in the 18 century and earlier. In European countries, including Russia, as well as in the United States, thousands of people have received classical secondary education and university education for decades. Socially, a classical education, which opened the way to a university education and thus to a appropriate career was a component of the respective statuses. According to the American historian Fritz Ringer, in 1887-1890 the number of Prussian university students who would have come from the lower class of society or from the productive part of the middle class (trade and industry) was less than a third. In 1902, this value is already almost half, despite the fact that the total number of students has more than doubled during this period [3]. The educational and social-differentiative character of classical education becomes all the more obvious when we recall that during the nineteenth century, the teaching of sciences in universities almost completely switched to national languages.

The difference between this attitude to historical knowledge and the approach of Renaissance Humanism is, first of all, that the history for the humanist is the path to the ancient spiritual homeland, the primary source of his identification as a personality, and the source of ideas for arrangement of the human community, while in the education system of the XIX century, historical knowledge and antiquity itself turn into a means of upbringing. Here it is important to take into account that the humanists for whom the above mentioned can be counted several hundred, while hundreds of thousands received classical education in 
the XIX century. Subject to the foregoing, this is not unexpected. In order to build a system of self-identification, an alternative to the dominant one, it is necessary to be an extraordinary person - this is how we characterize the humanists of the Renaissance, and in order to pass the classical gymnasium and university in the nineteenth century, it was enough to have average intellectual abilities and volitional efforts that found support in the social status (origin) of the student and, at the level of secondary education, in physical punishments. Social and cultural identification followed different paths, leaving history to reign, but not to rule, so that the real devaluation of historical knowledge remained hidden behind the culture facade of the nineteenth century.

\section{Discussion}

It may seem that the system of mass upbringing of the elite and the middle class, built on immersion in ancient culture, demonstrates a kind of forced capitulation of society to modernity, the recognition of its inability to build a system of effective life guidelines in the coordinate system at present. However, that's not true. It is not an inability to navigate in the present, but a partly conscious, partly unconscious reluctance. As noted above, the European consciousness, since the Renaissance Epoch, is a historical consciousness, that is thinking in terms of history and having individual and collective historical memory (commemoration). This historical consciousness makes the past relevant and effective, but at the same time allows to clearly distinguish between the past and the present, history and modernity. This feature of the modern European consciousness is characterized by Spengler: "... the ancient culture did not possess the memory, a historical body in this specific sense. The "Memory" of ancient man ... is something completely different, since here the past and the future are absent as the ordering perspectives of vigilant life, and everything is filled with a power decidedly unknown to us by the "pure present" ..." [4]. In the European education system and upbringing, antiquity, which first received from Romanticism the exalted status of an ideal that leads away from the philistine reality of capitalism and the state was taken with a full awareness of the time distance, in fact as an ideologeme that represents an alternative and the antithesis of the search for understanding the present and the future in the present itself.

The danger of this situation was clearly realized by Nietzsche, who was the first to critically raise the question of historical knowledge and its place in the modernity culture. Nietzsche wrote in particular that "... history can only be endured by strong personalities, while it completely suppresses the weak" [5]. From his point of view, the harm of historicism is that the real purpose of upbringing - to learn to live - is lost in the study of the past, and the ability to make decisions independently is destroyed by the habit of turning to the past for advice. History should take its place as the knowledge necessary for life, but it should not undermine it, turning into a "historical disease". Nietzsche's recommendations for overcoming this disease sound rather vaguely. We are talking about the need to "return to our true needs, famishing the imaginary needs", to sense once more and restore culture not as something that cultivates, i.e. serves as a "disguise and cover" for what is actually anticultural, but as an extension and continuation of the very humanity [6]. We shall see below how Spengler's idea gets more concrete content as follows.

In the described system of upbringing and education, elements of newly emerged ideologies were almost conflict-free combined with the classical legacy, firstly, nationalist ideologies that grew during the nineteenth century, and, secondly, progressive ideologies. Modernity inevitably penetrated the barriers of the system of education and upbringing, and very soon it became clear that this allows to introduce an ideology that benefits the elites. A succinct formulation is given by the American historian and philosopher of history - Alan Megill: "In the nineteenth, the discipline of history was very closely linked to the expansion of the power of the European nation-state. In Germany, France, and England, as in the United 
States, the historical discipline, which had recently become a profession, tended to serve as the ideological support of the state. ... Each case had its own dominant narrative - the "master narrative" - which covered the entire history of the nation, describing its development from the very beginning, through the awakening and growth of national consciousness, and up to the current struggle for its recognition and triumph" [7].

To a certain extent, experience and developed skill, even, the habit of historicism, made it very easy to spread ideologies - quasi-scientific, but comprehensible constructions. And if the well-educated representatives of the elite and the middle class could at any time criticize any ideology and, in any case, not follow it blindly, then the masses who had just appeared in the social arena had no immunity against ideologies. Ortega y Gasset in the 30 of the twentieth century described this social-psychological phenomenon: “... the specificity of our time is not that mediocrity considers itself extraordinary, but that it proclaims and asserts its right to vulgarity ... previously, in European history, the rabble had never been got wrong in regards to their own "ideas" concerning anything" [8]. The assessment given to the ideologies by Ortega y Gasset is unambiguous: "... the ideas of the mass man are not ideas actually, and he has not acquired a culture. The idea is the Check to the truth" And further: "... his "ideas" are nothing but verbal appetites, like heart-rending romances" [9].

In a large number of cases, the elites did not want to see the inevitability of the process of masses emancipation, could not accept the approaching loss of status and other cultural and social shifts that accompany the formation of an industrial society. To recognize the onesidedness and even uselessness of classical education, as well as the social barriers to university admission, would be to recognize the equal humanitarian value of the natural, mathematical, and technical sciences, and with them the new social sciences-economics, sociology, and political science. However, it is worth allowing the representatives of these sciences to speak too loudly, as the knowledge they communicate will begin to call into question the established order. Therefore, it is not surprising that at the time when Max Weber and Georg Simmel were creating their pioneering works on sociology and political science, the majority of the scientific and educational community in Germany rejected the need for an empirical and practically oriented study of social phenomena, insisting on the priority of a value-based approach to them [10]. In other words, historical knowledge in a crisis situation has become one of the tools of social and value confrontation.

The combination of the unprecedented rise of the sciences with the flourishing of ideologies is now explicable. When critically analyze classical education and the university of the nineteenth century, we shall not lose sight of their extraordinary productivity. The nineteenth century is a century of remarkable growth in European science, and it was in Germany, where the educational system described above was generated earlier than in other countries, that such quantitative and qualitative successes were achieved that by the beginning of the twentieth century Germany was the world center of all sciences without exception. But the class principle of education and the distribution of social positions was preserved, as well as the prejudices of the elite, and the same Germany gives us an example of the greatest exposure of the masses to ideological influence both from the authorities and from various opposition political forces. Finally, there are ideologies that are extremely far removed from historical and social reality. The elite continues to ignore these phenomena, considering them unimportant and being convinced that ideologies are needed to drain the energy of the masses, and the masses, continuing to maintain the existing social order and habitually leaving the power and expert functions to the elite, do not feel any responsibility when plunging into the world of certain ideological illusions. The chance to form a society the various classes representatives of which would be responsible bearers of its fundamental values was not used, and only later, during and after the end of the First World War, when the crisis of European culture became obvious, questions could not but arise on why the humanistic education of Europeans, essentially connected with historical knowledge, and 
with it their advanced science, poorly played their intended social role, and why it was in Germany, which achieved the greatest success, that their failure was the most extensive and dramatic.

Is there a connection here? Spengler gave the answer that covers all European humanity. From his point of view, at the turn of the nineteenth-twentieth centuries, Europe found itself in a situation of "historical junction of times, which occupied a predetermined place in the course of centuries within the precisely established boundaries of a large historical "organism"" [11]. This predestined historical crisis belongs to history as a form of movement, i.e., it has a "morphological" character for it, and it consists, in Spengler's terminology, in the organic dynamics of culture, culminating in the state of civilization as the "inevitable fate of culture". Spengler characterizes the features of civilization as follows: this is the final state of any particular culture, which precedes its destruction, this is the ossification of its forms, these are "most extreme and most artificial states", which are no longer capable of producing new values and realize themselves in the expansion, the manifestation of which is imperialism. This characteristic of the epoch allows to correctly prioritize and understand what is valuable and what is not. Spengler, following Nietzsche, calls for a radical change of orientation here. Reality, modernity, "living life" are declared to be much more valuable than the lifeless manifestations of civilization: "For the luxuriously clear, highly intelligent forms of some express steam vessel, steel factory, precision apparatus, the ingeniousness and elegance of other chemical and optical procedures, I will give all the stylish junk of today's applied arts, with painting and architecture. I prefer the Roman aqueduct to all Roman temples and statues" [12].

Summarizing the above, we shall list the reasons essential for historical epistemology that led to loss of the leading position in the system of social and humanitarian knowledge by historical science and historical knowledge during the cultural crisis. These include the emancipation of the masses and the destruction of the class structure of society, the spread of ideologies, industrial capitalism and the formation of a consumer society, imperialism (as a stage of more modern globalization), the development of science and technology, in particular, military, and, finally, the collapse of the status of humanitarian and, first of all, historical knowledge, with its displacement by other forms of social knowledge and social practice. An attempt to interpret the phenomenon of revaluation of historical knowledge in an crisis epoch will lead to the conclusion that at the turn of the nineteenth and twentieth centuries the system of cultural values collapsed, which combined the features of romantic idealism and the Enlightenment. The ability of rationality, including in the form of historical knowledge, to provide answers to key questions of human life and society has been questioned.

The epistemology of humanitarian knowledge cannot but be historical, i.e. it cannot leave out of consideration the social-cultural circumstances of the origin of knowledge. This is particularly significant for current state of historical knowledge, since the social functions of historical knowledge underwent a radical change during the twentieth century. Historical knowledge ceased to be at the center of the system of education and education of the elite as early as the crisis epoch at the beginning of the twentieth century, and its social tasks, which in the nineteenth century included the awareness and indication of the goals of life and the development of civilization, were transferred from the sphere of ideals to the practical sphere and moved to the new social sciences-economics, sociology, political science, etc. Today, it is not easy to answer the question whether we are still in a state of crisis or whether modern European culture has overcome it. But this question is connected with the question of the place and role of historical knowledge in modern culture. We will try to answer it below using the concept of the cynical reason of the German philosopher - Peter Sloterdijk. The justification of this approach is due to the fact that the crisis of culture is a crisis of values that occurs when these values are aware of the loss of their status. As a historical fact, such 
phenomenon can be recorded not only by studying social relations, for example, by means of sociology or historical science, but also by reconstructing people's value orientations through hermeneutic analysis of cultural phenomena, deconstruction of their meaning, assimilation and interpretive understanding, or artistic construction of the individual's inner world. In other words, the essence of the cultural crisis is expressed by evaluative rather than factual, judgments.

Analyzing the dynamics of the culture of the twentieth century, it is impossible not to see an impressive difference between the current state of European humanity and the state of the crisis period: at a high price, humanity has nevertheless learned to live in a reality that, having developed during the crisis and repeatedly changing the forms of its manifestations, has not yet lost its qualitative certainty. What appeared as a crisis and decline at the beginning of the twentieth century, functions as the norm at this time. And along with the entire cultural situation, the factors that determine the place and role of historical knowledge in culture have also remained: modernity has inherited them from the crisis period. In their current form, these should include, firstly, modernist and postmodern cynicism (in Sloterdijk's terminology), secondly, the democracy of social relations and processes, and thirdly, the high level of education, culture and social sophistication of the developed societies members, fourthly, the decline in the prestige of professional humanitarian knowledge and its displacement into the background by social sciences and technologies, as well as the position of common wisdom, which publicists and journalists express on behalf of society as a whole.

Factors mentioned in this study and determining the place and role of historical knowledge in culture may be demonstrated in the following figure 1:

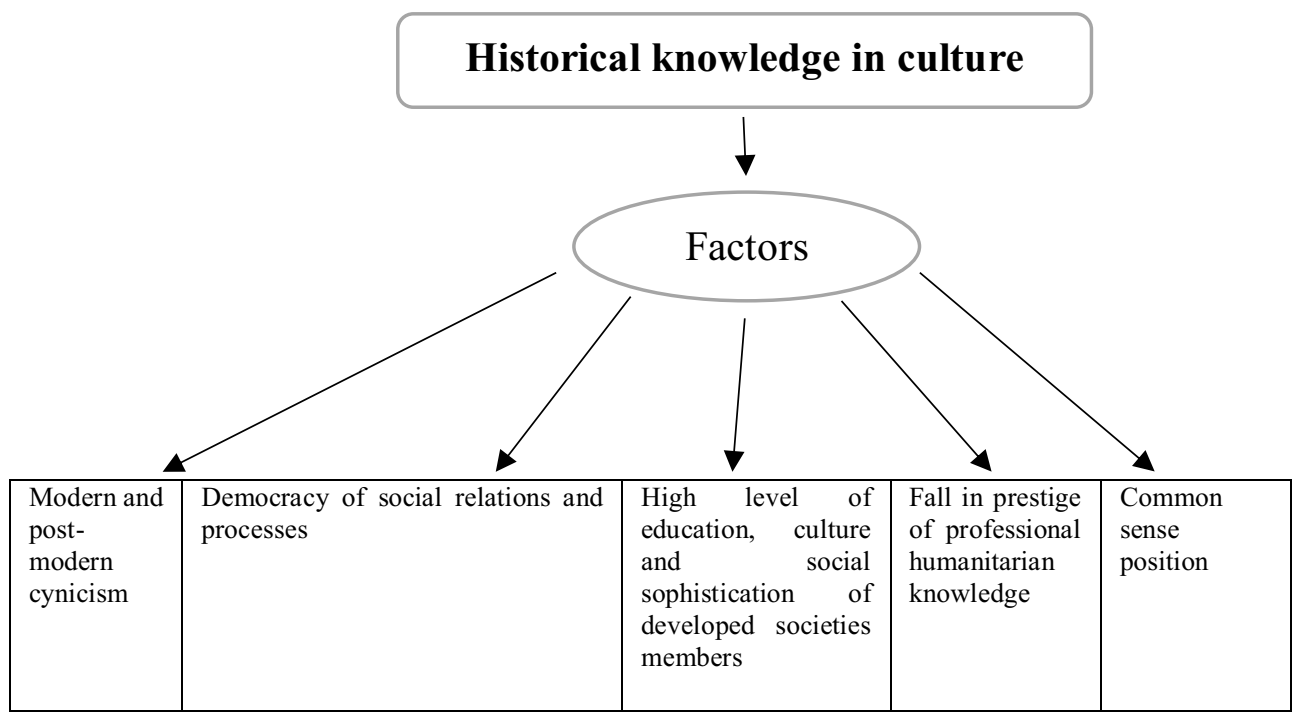

Fig. 1. Historical knowledge in culture.

There is no need to explain and justify the last three factors, since they make up the characteristics of sociocultural environment of historical knowledge modern existence. Sloterdijk's thoughts on the nature of modern reason deserve closer attention.

In his famous book "Critique of Cynical Reason" (1983) Sloterdijk subjects the new order of life, attitudes and values that has developed in the countries of European culture in the post-war era to philosophical and cultural criticism, in the process of the formation of a postindustrial consumer society, exporting its way of life to all corners of the world with an increasing speed. The central diagnostic idea in Sloterdijk's concept is cynicism defined as "enlightened false consciousness" [14]. In the history of consciousness the cynicism follows 
other three forms of false consciousness which are lies, delusion and ideology. Replacing each other they clear the way for cynicism. The reason having learned to distinguish truth from the lie comes, at the same time, to the understanding of the relativity of these concepts and the antinomy of some of its manifestations. The enlightenment fights against delusion, prejudice, evil will and abuse of power unwittingly giving priority to equality but not freedom in the fury of its fight, and, ultimately, denying its grounds. Criticism of ideological messages showed their danger and at the same time, the insignificance and pathology, on the one hand, and their nonremovability even in the very grounds of criticism. Passing these stages or states the reason kept in itself each of the acquired capabilities, recorded the experience, and therefore its resulting cynicism is the result of clear-eyed experience. "Doing the worst, knowing the best - this formula ... claims to express a systematic approach, to become a model for making a diagnosis" [15]. Clear mind and expertise are expressed here in line with the insolence challenging the ideals that continue to be realized in the mode of the must. At the same time, not only ignoring of the must, but also a claim to happiness appear in cynical insolence. In general, “... a specific, unique feeling of timelessness arises in the cynical dusk light - a feeling which joint together the desire to act feverishly and confusion, the desire to undertake something and despondency, a feeling that cannot escape from everyday life circle, which alienated from history and got out of a habit to enjoy the future. ... The past either becomes a spoiled child who is being made much by academic science, or is privatized along with culture and history, turning into a junk man shop which comprises curious miniatures certifying that once everything has happened already in the past. The greatest interest is caused by the biographies of people of the past and long-forgotten kings, and first of all, the pharaohs - as eternally living and comfortably arranged corpses with which we can identify ourselves" [16]. This ahistoricity specified by Sloterdijk is not an ahistoricity of the knowledge by itself but arises as a result of the emphasized differentiation of knowledge from action. You can know the past and know the must but if there is no confidence in fundamental possibility to achieve a positive result of its action the enlightened reason chooses the path of uncertain judgement, including historical, and abstention from action.

In the modern epistemology of historical knowledge this position is theoretically substantiated by Alan Megill, the American historian and philosopher of history. He sets forth the principle of indecisive dialectics or indecision following which the interpreter may not take any of the possible positions in relation to a historical event, but takes them all into account, offering the listener or reader possible estimates of their credibility. In so doing the intention to put knowledge of history outside of political, social or educational tasks is clearly declared and this allows a scientist to reduce to a minimum the level of his responsibility for social consequences of the spread of knowledge.

The phenomenon of cynical reason was discovered by Sloterdijk while studying the history of the Weimar Republic. The significant illustrative material is presented on this particular subject in the historical part of his book, allowing to see the manifestations of the cynical reason in its various forms. But the immediate historical background for Sloterdijk was the Cold War era which was a difficult time for Germany and which ended shortly after the publication of his book. The specific character of that time has receded into the background today, since it was replaced by a rosy period of detente, disarmament, rapid economic growth and international cooperation. But if we recall the European realities of the 70 s and early 80 s, the "dusk light" and "timelessness" that Sloterdijk writes about will be appropriate symbols of fatigue of confrontation and threat of a new world war. Post-war cynicism for the Germans, as opposed to revanchist Weimar one, reflected mainly the doubts and uncertainty along with a sense of historical guilt, rather than audacity to happiness.

Even if we make allowance for specified circumstances Sloterdijk's analysis of modern consciousness as cynical seems to be correct. The characteristics of the current state of culture can be given without using the term "cynicism" of course, especially since there is no 
shortages in such characteristics. But Sloterdijk's concept is successful by the reason that cynicism is understood by it not like a life orientation, not like characteristic of the reason (the title of the book contains metonymy), consciousness or mental health, and is not also a measurable characteristic of the society. Sloterdijk's cynicism should be understood as a general mode of realization of all and every cultural (value-based) and social relations. Alternative terms such as "relativism", "skepticism", "anomie', etc., would refer us to the bearers of values and attitudes and would distort the impression. Indeed, these characteristics would be incorrect for the inner world of beliefs and experiences. Modern European culturebearer in terms of his beliefs is rather not cynical, not a relativist, sceptic and not anomic, although in many situations he behaves as if he has these features. This paradoxical situation is explained mainly by the nature of the communicative interactions of our time. A member of civil society of equals, who is a modern European culture-bearer, is assigned the rights that he is not able to use, and a responsibility which seems to him unclear, multiple-aspect but inevitable. The intensity of rueful feelings experienced by the subject of this situation ranges from indifference to panic, while the prevailing state is the state which Niklas Luhmann describes as "fear". This fear, by its nature, is not associated with any specific situations, but is present as a background against which social relations are carried out. It is even more difficult to find another one - the one who is guilty of the current situation. To do this would mean finding oneself in a real conflict, that is, move forward to meet those dangers, the avoidance of which lies in the basis of modern social consciousness. Indeed, in the 20th century, particularly in its second half, the direction of the movement of societies was determined by striving to get rid of the misfortunes of wars, totalitarianism, violence and lawlessness rather than progress and happiness. Therefore, whereon the formation of a development strategy on a global scale could be expected on the basis of mankind's sophistication in historical and social knowledge the modernity reveals unexpected absence of any strategy. It is easy to see that globalization happens as a natural consequence of the global differentiation of labour and unintentional spread of Western living standards from no part. Having learned to live avoiding disasters the mankind with its current anamnesis has lost the motive to develop a positive program of action. Nothing causes really serious concern, and therefore it is not possible to form concerned communication discourse outside of which any calls will remain unheard. While historical experience teaches cynicism refraining from positive judgement and action.

The project of arranging the mankind, rising to the Enlightenment in the person of JeanJacques Rousseau and Immanuel Kant, as a global civil community or a global city-state which preserves intense individual communication of each with the social whole proved to be unrealizable due to immensely increased and complicated functions of individual existence in society rather than due to the scale. Self-regard extends today to the achievement and retention of social status rather than to material consumption. Ceasing to care about this would mean destroying the basis for ordering modern society, and, while maintaining it, it is impossible to go beyond the limits of the social being the closest to you. Roughly speaking, a modern person concerned with his everyday life does not have time and energy for the entire mankind, and this circumstance is a constitutive property of modern mankind which holds it together and, at the same time, deprives it of the ability to large-scale action.

The formula for creating and reconstruction of civil communities can hardly be found. Sloterdijk puts forward just a desired direction: "People must proceed from the fact that even if the entire area is covered with a white shroud, they manage to treat each other with such a seriousness in a specially built internal space, as if there are no external factors. Couples, communes, choirs, teams, peoples and churches - all of them, without exception, are meant to create a fragile space to take shelter from the mighty white hell. Only in such self-made vessels becomes real what the most radical semantic layer of the faded word "solidarity" implies. The target of the modern art to live is an achievement of unindifferent in indifferent". 
In other words, not claiming the globality it is necessary to proceed to restoration of local communities. The starting point for this should be some new human concern with modernity rising from thinking through to the end the features of the cynical reason and the reality created by him. The critical role belongs, therefore, not to historical, but to social and cultural and critical judgement.

The history considered from this perspective, while remaining an irreplaceable reality of the world picture for human and mankind, ceases to be evaluated as an objective force that "grinds" people, nations and humanity. When occurrence of a universal human catastrophe technologically comes to pressing the "red button", those who stand next to it, if pathological cases are excluded, are unable to transfer responsibility to historical circumstances and laws of nature, no matter how much the ideologists think about them beforehand or post factum. The ability to decide the fate of a mankind just with one sweep sometimes turns history from an abstract movement of objective forces into a specific act of a specific person, whose motives, as he himself discovers, do not lie in the series of historical laws at all. On the other hand, modern societies are much more stable than ever in the past by the reason that they are fragmented, dominated by horizontal interrelations, and the centre is distributed and it is difficult to distinguish it from the periphery. This is a crucially new situation in which any social action quickly fades away, so that even the most daring terrorist attacks prove to be vain. It turns out that acting, on the one hand, is extremely dangerous, but on the other hand, it is practically useless, and within the framework of this antinomy it is easier to let things go their own way, which is not the path of history, i.e. not created by sense-bearing and goaloriented actions of people, will of the masses, and even by certain laws which are apparent in the optics of historical knowledge. Reality turns out to be too complicated mixture of all together, so that history can only happen as a history of some of its fragments. Total history is being fragmented, never taking place.

\section{Results}

The event in this reality turns into the central phenomenon of history and the most demanded part of historical knowledge available directly. In its structure an event is something that can be projected onto yourself. Historical laws, "history lessons", historical criticism of politics, ideology, social classes and organizations do not cause such interest as an event itself. The non-event cannot be otherwise presented in the form of judgements claiming the credibility which the cynical reason of our time being sophisticated by sciences and which is free in decisions, truly saying does not believe in. The authority of soft scientist has been irrevocably lost and cannot support the historical judgement, and the government, as soon as it tries to use the historical as an instrument of propaganda, cynically not believing in what it says, and cynically laughing at its own attempt to manipulate the society, turns itself the historical from propaganda instrument (classically - heavy-weight instrument) into a PR instrument (cynical - lightweight instrument). In such a way the didactic and propaganda functions of historical knowledge are degenerating, and there is only one thing left for it - to satisfy the demand for events of the past.

So it is easy to understand the reason of popular history prosperity, the growth of mass interest in memoirs, biographies, essays on everyday life and customs, historical cinema nowadays which reconstructs the events of past in detail and authentically (costumes, hairstyles, interiors, etc.), and the reason of the attention of non-specialists to archive materials, in particular documents containing statistical data. Interest in a historical event appears now not only in an interest in its assessment and interpretation by a professional historian, but also in an interest in materials that can become a basis for such interpretation. Two centuries of historical education, including a century of mass study of history and other social sciences, have formed an audience of millions, in which everyone is willing and can 
be (worse or better) an interpreter of one or another data, facts, actions and events. Moreover, the intended endeavour to understand the history independently turns out to be the element of modern freedom. The right to own the past individually definitely opposed to the old exclusive right of the elite, cannot be disputed and is assumed in the role of one of the gains of a society of equals. The ignoramus arrogance which presents here is not afraid of failure, because the adequacy of understanding of the historical phenomenon is not necessary. The goal is the desire to rather expand personal event-related experience, collect exotic excitement. The forms of the modern existence of popular historical knowledge mentioned above serve to achieve this goal. Abstaining from significant social actions, the human of our time feels the lack of events in his own time and tries to compensate it by learning events of history, expanding his experience and, at the same time, mastering the past. Popular history helps to achieve this through approaching the art in genre respect and pulling the past into an event, just as art pulls a phenomenon into an image. Historical knowledge is in demand by the present times in a new quality - as one of the dream factories.

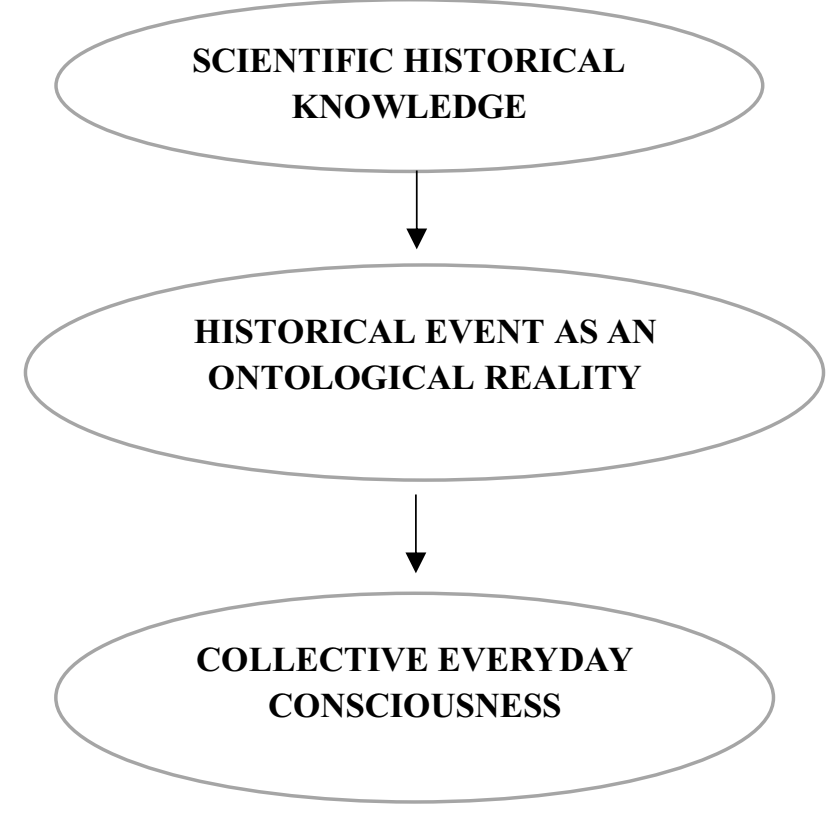

Fig. 2. The process of scientific historical knowledge.

Today the history remains as an element of the picture of the world, and its comprehension is not only the exclusive prerogative of historical knowledge, but it is attributed to the task of the group of social sciences (economics, legal science, sociology, political science, social psychology, ethnology), among which the history as a science occupies a peripheral position. The same group of sciences also performs the tasks related to current social analysis, forecasting and management in which historical science is not involved. At the same time, historical knowledge is in demand by present times in a new capacity, namely, as a source of experience of going through the historical event claiming to approximate the immediate. This allows us to assume the existence of an epistemological pattern: the spread of mass ignoramus forms of knowledge becomes a symptom of simplification of social functions and lowering of the knowledge system status that has been developed at the previous stage of cultural development. 


\section{References}

1. L.V. Balakhonskaya, V.I. Strelchenko, V.V. Balakhonsky, T.A. Sadretdinova, I.V. Beresneva, Communicative strategy of discrediting opponents in the russian political blogosphere, 2020 IEEE Communication Strategies In Digital Society Seminar, COMSDS 2020 Proceedings, p. 27-33( 2020)

2. V.I. Strelchenko, The problem of truth-value identification, The bulletin of Russian State Pedagogical University after Gertsen A.I. 175, 105-115 (2015)

3. J. Baudrillard, Simulacra and simulations (M., 2017)

4. V.V. Balakhonsky, O.D. Shipunova, V.I. Strelchenko, L.V. Balakhonskaya, Yu.V. Beresneva, Motivation factors for political consciousness formation in the modern world, International journal of criminology and sociology 9, 941-949 (2020)

5. P. Feyerabend, Science in a Free Society (M.: Canon, 2011)

6. V.V. Balakhonsky, M.V. Bakhtin, V.I. Strelchenko, Models and philosophical and epistemological representation of history (M.: Entsiklopedist-Maksimum, 2017)

7. V.A. Lektorskiy, Ye.O. Truphanova, Constructivism in epistemology and in human sciences, Human 30, 1, 102-124 (2019)

8. L.A. Nikiforov, Science transformation in the 20th century: from the search for truth to the improvement of technology, Epistemology \& philosophy of science 56, 3, 20-29 (2019)

9. I.T. Kassavin, Knowledge and reality in historical epistemology, Epistemology \& Philosophy of Science 57, 2, 6-19 (2020)

10. K. Jaspers, The meaning and purpose of history (M.: Respublika, 1994)

11. E. Husserl, The Crisis of European Sciences and Transcendental Phenomenology. [Electronic media] https://filosoff.org/edmundhusserl/tvorchestvo/krizis-evropejskixnauk-i-transcendentalnaya-fenomenologiya/ (application date: 27.03.2021)

12. R. Feynman, R. Leighton, The Feynman Lectures on Physics: 9 volumes. V. 1 (M. 2016)

13. B. Latour, Reassembling the social. An introduction to actor-network-theory (M.: Higher School of Economics Publishing House, 2014)

14. R. G. Collingwood, The Idea of History. Autobiography (M.: Nauka, 2015)

15. I.B. Mikirtumov, Philosophical Logic: Trilemma of Nomology, "Sociology" and "Physiology" (On the Release of the Book of E.G. Dragalina-Chernaya "Informal notes on logical form"), Philosophy science Journal 1, 85-94 (2017)

16. S. Fuller, Making 'science as a public good' meaningful: response to stehr, turner and sassower, Epistemology \& philosophy of science 57, 4, 70-75 (2020) 